\title{
Corticotropin-Releasing Factor Within the Central Nucleus of the Amygdala and the Nucleus Accumbens Shell Mediates the Negative Affective State of Nicotine Withdrawal in Rats
}

\author{
Catherine A Marcinkiewcz', Melissa M Prado', Shani K Isaac', Alex Marshall', Daria Rylkova' and \\ Adrie W Bruijnzeel*,I
}

'Department of Psychiatry, College of Medicine, University of Florida, Gainesville, FL, USA

\begin{abstract}
Tobacco addiction is a chronic disorder that is characterized by a negative affective state upon smoking cessation and relapse after periods of abstinence. Previous research has shown that an increased central release of corticotropin-releasing factor (CRF) at least partly mediates the deficit in brain reward function associated with nicotine withdrawal in rats. The aim of these studies was to investigate the role of CRF in the central nucleus of the amygdala (CeA), the lateral bed nucleus of the stria terminalis (BNST), and the nucleus accumbens shell (Nacc shell) in the deficit in brain reward function associated with precipitated nicotine withdrawal. The intracranial selfstimulation procedure was used to assess the negative affective aspects of nicotine withdrawal. Elevations in brain reward thresholds are indicative of a deficit in brain reward function. In all experiments, the nicotinic receptor antagonist mecamylamine $(3 \mathrm{mg} / \mathrm{kg})$ elevated the brain reward thresholds of the nicotine-dependent rats $(9 \mathrm{mg} / \mathrm{kg}$ per day of nicotine salt) and did not affect the brain reward thresholds of the saline-treated control rats. The administration of the nonspecific CRFI/2 receptor antagonist D-Phe CRF(I2-4I) into the CeA and the Nacc shell prevented the mecamylamine-induced elevations in brain reward thresholds in the nicotine-dependent rats. Blockade of $\mathrm{CRFI} / 2$ receptors in the lateral BNST did not prevent the mecamylamine-induced elevations in brain reward thresholds in the nicotinedependent rats. These studies indicate that the negative emotional state associated with precipitated nicotine withdrawal is at least partly mediated by an increased release of CRF in the CeA and the Nacc shell.

Neuropsychopharmacology (2009) 34, 1743-1752; doi:I0.1038/npp.2008.231; published online I4 January 2009
\end{abstract}

Keywords: nicotine; corticotropin-releasing factor; dependence; reward deficit; rats

\section{INTRODUCTION}

Tobacco addiction is a chronic disorder that is characterized by loss of control over smoking, the appearance of withdrawal symptoms upon smoking cessation, and relapse after periods of abstinence (American Psychiatric Association, 2000; McLellan et al, 2000; O'Brien, 2003). Abrupt cessation of smoking typically mediates negative affective symptoms such as depressed mood, anxiety, irritability, and difficulty concentrating (American Psychiatric Association, 2000). It has been hypothesized that the negative affective aspects of tobacco withdrawal provide a powerful motivation for the continuation of smoking (Koob et al, 1997; Markou et al, 1998). Experimental evidence suggests that nicotine is one of the main components of tobacco smoke

\footnotetext{
*Correspondence: Dr AW Bruijnzeel, Department of Psychiatry, University of Florida, 100 S. Newell Dr, PO Box 100256, Gainesville, FL 326 I0, USA, Tel: + I 352294 0421, Fax: + I 352392 82 17, E-mail: awbruijn@ufl.edu

Received 26 August 2008; revised 10 November 2008; accepted 24 November 2008
}

that leads to and maintains the tobacco addiction (Bardo et al, 1999; Crooks and Dwoskin, 1997; Stolerman and Jarvis, 1995). The positive reinforcing effects of nicotine are at least partly mediated by the activation of neuronal nicotinic acetylcholine receptors (nAChRs). Blockade of nAChRs decreases the self-administration of nicotine in rats (Corrigall et al, 1994; Corrigall and Coen, 1989; Donny et al, 1999; Watkins et al, 1999). In addition, mice that lack the $\beta 2$-subunit of the nAChR self-administer less nicotine than wild-type controls (Picciotto et al, 1998). Nicotine withdrawal is associated with a deficit in brain reward function and somatic withdrawal signs in rats (Bruijnzeel and Markou, 2004; Epping-Jordan et al, 1998; Harrison et al, 2001). Epping-Jordan and colleagues reported that systemic administration of the $\mathrm{nAChR}$ antagonist dihydro- $\beta$ erythroidine induces an elevation in brain reward thresholds (decrease in the reinforcing properties of intracranial self-stimulation, ICSS) and an increase in somatic withdrawal signs in rats chronically treated with nicotine. Similarly, abrupt cessation of nicotine administration mediates an elevation in brain reward thresholds and an increase in somatic withdrawal signs (Epping-Jordan et al, 
1998). The administration of nicotine after the discontinuation of chronic nicotine administration has been shown to mitigate somatic nicotine withdrawal signs (Malin et al, 1992). These findings indicate that nicotine stimulates the brain reward system and discontinuation of chronic nicotine administration leads to a negative emotional state in rats.

Accumulating evidence suggests that a hyperactivity of brain stress systems may lead to a deficit in brain reward function, which is one of the core symptoms of drug withdrawal and depression (Barr and Markou, 2005; Bruijnzeel and Gold, 2005). Clinical studies indicate that brain corticotropin-releasing factor (CRF) systems are hyperactive in patients with depressive disorders (Nemeroff et al, 1984; Zobel et al, 2000). Preclinical research indicates that intracerebroventricular (i.c.v.) administration of CRF induces an elevation in brain reward thresholds in rats, which is indicative of a deficit in brain reward function (Macey et al, 2000). The observation that increased CRF transmission is important in negative affective states has stimulated research into the function of CRF in drug addictions. These studies have provided evidence for a function of CRF in drug withdrawal-induced anxiety-like behavior. Blockade of CRF receptors has been shown to decrease anxiety-like behavior associated with withdrawal from alcohol, cocaine, and other drugs of abuse (Baldwin et al, 1991; Basso et al, 1999; Overstreet et al, 2004; Rassnick et al, 1993; Sarnyai et al, 1995). Moreover, in a recent study we demonstrated that the i.c.v. administration of the nonspecific CRF1/2 receptor antagonist $\mathrm{D}-\mathrm{Phe} \mathrm{CRF}_{(12-41)}$ prevents the elevations in brain reward thresholds associated with precipitated nicotine withdrawal in rats (Bruijnzeel et al, 2007).

Although extensive progress has been made into the understanding of the function of CRF in drug withdrawal, it is not known through which specific brain sites CRF mediates the deficit in brain reward function associated with nicotine withdrawal. Experimental evidence points toward a function for the central nucleus of the amygdala (CeA) and the lateral bed nucleus of the stria terminalis (BNST) in the negative emotional state associated with nicotine withdrawal. Spontaneous alcohol and cocaine withdrawal and precipitated cannabinoid and nicotine withdrawal have been shown to elevate extracellular CRF levels in the CeA (George et al, 2007; Merlo Pich et al, 1995; Richter and Weiss, 1999; Rodriguez de Fonseca et al, 1997). In addition, alcohol withdrawal increases the release of CRF in the BNST, which can be reversed with subsequent alcohol intake (Olive et al, 2002). Another brain site that has been suggested to be important in drug addiction is the nucleus accumbens shell (Nacc shell). It has been suggested that the negative emotional state associated with drug withdrawal is at least partly mediated by a hypodopaminergic function in the Nacc shell (Barr et al, 2002; Rada et al, 2001). Although CRF and its receptors have been detected in the Nacc shell, there is no experimental evidence suggesting the importance for CRF in the Nacc shell during drug withdrawal (De Souza et al, 1985; Swanson et al, 1983). The administration of CRF into the lateral ventricles has been shown to induce behavioral activation in rats in a familiar environment, which is indicative of increased arousal and anxiety-like behavior, and a similar effect has been observed after the administration of CRF into the Nacc shell (Holahan et al, 1997). This suggests that the release of CRF into the Nacc shell could contribute to negative emotional states.

Taken together, the above-discussed studies suggest that increased CRF transmission may be important in the negative mood state associated with nicotine withdrawal. In addition, the $\mathrm{CeA}$, BNST, and Nacc shell have been suggested to have an important function in drug withdrawal and/or relapse to drug seeking behavior (Koob, 2008). The aim of these experiments was to investigate the function of CRF in the CeA, lateral BNST, and Nacc shell in the deficit in brain reward function associated with precipitated nicotine withdrawal in rats. The effect of the administration of the nonspecific CRF1/2 receptor antagonist $\mathrm{D}$-Phe $\mathrm{CRF}_{(12-41)}$ (CRF1 receptor, $\mathrm{Ki}=56 \mathrm{nM}$; $\mathrm{CRF} 2$ receptor, $\mathrm{Ki}=5.2 \mathrm{nM}$ ) into the CeA, lateral BNST, or Nacc shell on the elevations in brain reward thresholds associated with precipitated nicotine withdrawal was investigated by using a discrete trial ICSS procedure (Gulyas et al, 1995; Perrin et al, 1999). This procedure was used to assess the negative affective aspects of nicotine withdrawal as it provides a quantitative measure of the emotional aspects of drug withdrawal (Bruijnzeel et al, 2006; Schulteis et al, 1995; Wise and Munn, 1995). In all of the experiments, response latencies were assessed to determine if the administration of the CRF receptor antagonist into the specific brain sites would affect motor output (Markou and Koob, 1992). Experiments that provide insight into the specific function of brain stress systems in the negative affective aspects of nicotine withdrawal may contribute to the development of nonaddictive pharmacotherapies that reduce tobacco withdrawal symptomatology and improve relapse rates.

\section{MATERIALS AND METHODS}

\section{Subjects}

Male Wistar rats (Charles River, Raleigh, NC) weighing 250$300 \mathrm{~g}$ at the beginning of the experiments were used. Animals were group-housed (two per cage) in a temperature- and humidity-controlled vivarium and maintained on a $12 \mathrm{~h}$ light-dark cycle (lights off at 1800 hours). All testing occurred at the beginning of the light cycle. Food and water were available ad libitum in the home cages. All subjects were treated in accordance with the National Institutes of Health guidelines regarding the principles of animal care. Animal facilities and experimental protocols were in accordance with the Association for the Assessment and Accreditation of Laboratory Animal Care and approved by the University of Florida Institutional Animal Care and Use Committee.

\section{Drugs}

Nicotine hydrogen tartrate salt, mecamylamine hydrochloride, and pentobarbital sodium salt were purchased from Sigma (Sigma-Aldrich, St Louis, MO, USA) and dissolved in sterile saline $(0.9 \%$ sodium chloride). The CRF1/2 receptor antagonist [D-Phe $\left.{ }^{12}, \mathrm{Nle}^{21,38}, \mathrm{C}^{\alpha} \mathrm{Me} \mathrm{Leu}^{37}\right] \mathrm{r} / \mathrm{hCRF}_{(12-41)}$ (D-Phe $\mathrm{CRF}_{(12-41)}$ ) was synthesized by The Clayton Foundation Laboratories for Peptide Biology and kindly provided by Dr Jean Rivier (Salk Institute for Biological 
Studies, La Jolla, CA). D-Phe $\mathrm{CRF}_{(12-41)}$ was dissolved in distilled water and kept on ice until being used in the behavioral experiments. The CRF receptor antagonist was administered within $1 \mathrm{~h}$ after being dissolved.

\section{Surgical Procedures}

Cannulae and electrode implantations. At the beginning of all the intracranial surgeries, the rats were anesthetized with an isoflurane/oxygen vapor mixture (1-3\% isoflurane) and placed in a Kopf stereotaxic frame (David Kopf Instruments, Tujunga, CA) with the incisor bar set $3.3 \mathrm{~mm}$ below the interaural line (flat skull). The rats were prepared with $11 \mathrm{~mm}$ stainless steel 23 -gauge cannulae above the CeA, lateral BNST, or Nacc shell using flat skull coordinates according to Paxinos and Watson, 1998, and a previous study by Koob and colleagues (Funk et al, 2006). Bilateral cannulae were implanted $2.5 \mathrm{~mm}$ above the CeA (anteriorposterior (AP) -2.3 , medial-lateral (ML) $\pm 4.0 \mathrm{~mm}$, dorsalventral (DV) -4.7 from dura), $2.0 \mathrm{~mm}$ above the lateral BNST (AP $-0.6, \mathrm{ML} \pm 3.7$ and $15^{\circ}$ vertical tilt, DV -4.6 from dura), or $2.5 \mathrm{~mm}$ above the Nacc shell (AP $+1.7 \mathrm{~mm}$, ML \pm 1.0 , DV -5.1 from dura). At the end of the surgery, $11 \mathrm{~mm}$ removable 30 -gauge wire stylets were inserted in the cannulae to maintain patency. For the electrode implantations, the incisor bar was set $5 \mathrm{~mm}$ (CeA and lateral BNST groups) above the interaural line or at the interaural line (Nacc shell group). The position of the incisor bar had to be adjusted for the electrode implantations in the Nacc shell group to accommodate the cannulae and the electrode. The rats were prepared with stainless steel bipolar electrodes (model MS303/2; Plastics One, Roanoke, VA) $11 \mathrm{~mm}$ in length in the medial forebrain bundle at the level of the posterior lateral hypothalamus (AP $-0.5 \mathrm{~mm}$, ML $\pm 1.7 \mathrm{~mm}, \mathrm{DV}-8.3 \mathrm{~mm}$ from dura). The electrodes and cannulae were permanently secured to the skull using dental cement anchored with four skull screws.

Osmotic minipump implantations. The rats were prepared with osmotic minipumps (model 2ML4, 28 day pumps; Durect Corporation, Cupertino, CA) filled with either saline or nicotine hydrogen tartrate dissolved in saline. The pumps were implanted subcutaneously under isoflurane/ oxygen (1-3\% isoflurane) anesthesia. The nicotine concentration was adjusted to compensate for differences in body weight and to deliver a dose of $9 \mathrm{mg} / \mathrm{kg}$ per day of nicotine salt $(3.16 \mathrm{mg} / \mathrm{kg}$ per day nicotine base).

\section{Apparatus}

The experimental apparatus consisted of 12 Plexiglas chambers $(30.5 \times 30 \times 17 \mathrm{~cm}$; Med Associates, Georgia, VT), each housed in a sound-attenuating melamine chamber (Med Associates). The operant conditioning chambers consisted of a metal grid floor and a metal wheel ( $5 \mathrm{~cm}$ wide) centered on a sidewall. A photobeam detector was attached next to the response wheel and recorded every $90^{\circ}$ of rotation. Brain stimulation was delivered by constant current stimulators (Model 1200C; Stimtek, Acton, MA). Subjects were connected to the stimulation circuit through bipolar leads (Plastics One) attached to gold-contact swivel commutators (model SL2C; Plastics One). A computer controlled the stimulation parameters, data collection, and all test session functions.

\section{Intracranial Self-Stimulation Procedure}

Rats were trained on a modified discrete-trial ICSS procedure (Kornetsky and Esposito, 1979), as described previously (Markou and Koob, 1992). The subjects were trained initially to turn the wheel on a fixed ratio 1 schedule of reinforcement. Each quarter turn resulted in the delivery of a $0.5 \mathrm{~s}$ train of $0.1 \mathrm{~ms}$ cathodal square-wave pulses at a frequency of $100 \mathrm{~Hz}$. After the successful acquisition of responding, defined as 100 reinforcements within $10 \mathrm{~min}$, the rats were gradually trained on a discrete-trial currentthreshold procedure. Each trial began with the delivery of a noncontingent electrical stimulus, followed by a 7.5-s response window within which the animal could respond to receive a second contingent stimulus identical to the initial noncontingent stimulus. A response during this 7.5-s response window was labeled as a positive response and the lack of a response was labeled as a negative response. During a 2-s period immediately after a positive response, additional responses had no scheduled consequences. The intertrial interval (ITI), which followed either a positive response or the end of the response window, had an average duration of $10 \mathrm{~s}$ (7.5-12.5 s). Responses that occurred during the ITI resulted in a further $12.5 \mathrm{~s}$ delay of the onset of the next trial. During training on the discrete-trial procedure, the duration of the ITI and delay periods induced by time-out responses were gradually increased until animals performed consistently at standard test parameters. The rats were subsequently tested on the current-threshold procedure in which stimulation intensities varied according to the classical psychophysical method of limits. A test session consisted of four alternating series of descending and ascending current intensities starting with a descending series. Blocks of three trials were presented to the subject at a given stimulation intensity, and the intensity was altered systematically between blocks by $5 \mu \mathrm{A}$ steps. The initial stimulus intensity was set $40 \mu \mathrm{A}$ above the baseline current-threshold for each animal. Each test session typically lasted $30-40 \mathrm{~min}$ and provided two variables: brain reward thresholds and response latencies. The brain reward threshold for a descending series was defined as the midpoint between stimulation intensities that supported responding (ie positive responses on at least two of the three trials), and current intensities that failed to support responding (ie positive responses on fewer than two of the three trials for two consecutive blocks of trials). The threshold for an ascending series was defined as the midpoint between stimulation intensities that did not support responding and current intensities that supported responding for two consecutive blocks of trials. Four threshold estimates were recorded and the mean of these values was taken as the brain reward threshold for a specific subject. The response latency was defined as the time interval between the beginning of the noncontingent stimulus and a positive response. The response latency for each test session was defined as the mean response latency on all trials during which a positive response occurred. 


\section{Intracerebral Microinjections}

The bilateral injections were administered by using 30 -gauge stainless steel injectors that extended $2.5 \mathrm{~mm}$ (length of injector tip, $13.5 \mathrm{~mm}$; CeA and Nacc shell) or $2.0 \mathrm{~mm}$ (length of injector tip, $13.0 \mathrm{~mm}$; lateral BNST) beyond the guide cannulae. The injection volume was $0.5 \mu \mathrm{l}$ per side and this was infused over $66 \mathrm{~s}$. The infusion speed was regulated by a Harvard Apparatus syringe pump (model 975) and the pump was equipped with $10 \mu$ l syringes (Hamilton, Rena, NE). The syringes were connected to the injectors with Tygon microbore PVC tubing $(0.25 \mathrm{~mm}$ ID $\times 0.76 \mathrm{~mm} \mathrm{OD)}$. The injectors were left in place for $30 \mathrm{~s}$ postinjection to allow diffusion from the injector tip. The dummy stylets, $11 \mathrm{~mm}$, were re-inserted immediately after the injectors were removed.

\section{Histology}

At the end of the experiments, the rats were killed with an overdose of sodium pentobarbital $(150 \mathrm{mg}$, intraperitoneally) and perfused through the ascending aorta with physiological saline $(100 \mathrm{ml})$ followed by a $10 \%$ phosphate buffered formalin solution $(150 \mathrm{ml})$. Brains were postfixed for $24 \mathrm{~h}$ and cryoprotected in $10 \%$ sucrose in phosphate buffered saline for $48 \mathrm{~h}$. Sections were cut on a Leica CM3050 S cryostat (coronal sections of $40 \mu \mathrm{m}$ at $-15^{\circ} \mathrm{C}$ ). The sections were mounted on Fisher Superfrost Plus slides and stained with cresyl violet. The locations of the guide cannulae and injections sites were verified with light microscopy and with reference to a stereotaxic atlas of the rat brain (Paxinos and Watson, 1998).

\section{Experimental Design}

Effect of $D$-Phe $C R F_{(12-41)}$ administered into the CeA, lateral BNST, or Nacc shell on precipitated nicotine withdrawal. Naïve rats were used for all the experiments. After recovery from the electrode implantations, the rats were trained on the ICSS procedure. When stable baseline brain reward thresholds were achieved (defined as less than $10 \%$ variation within a 5 -day period), the rats were prepared with 28-day osmotic minipumps containing either saline or nicotine dissolved in saline (CeA: saline $n=8$, nicotine $n=8$; lateral BNST: saline $n=9$, nicotine $n=9$; Nacc shell: saline $n=9$, nicotine $n=9$ ). Brain reward thresholds and response latencies were assessed daily throughout the experiment between 0900 and 1200 hours. The nAChR antagonist mecamylamine $(3 \mathrm{mg} / \mathrm{kg}$, s.c.) was used to precipitate nicotine withdrawal. Mecamylamine injections started at least 6 days after the implantation of the minipumps to allow time for the development of nicotine dependence. The CRF1/ 2 receptor antagonist $\mathrm{D}-\mathrm{Phe} \mathrm{CRF}_{(12-41)}(5-500 \mathrm{ng}$ per brain site, unilateral dose) was administered $10 \mathrm{~min}$ before treatment with mecamylamine. The rats were placed in the ICSS test chambers 5 min after mecamylamine administration. It was ensured that the minimum time interval between the mecamylamine injections was at least $72 \mathrm{~h}$ to reestablish/ maintain nicotine dependence. The serum elimination halflife of mecamylamine is approximately $1 \mathrm{~h}$ (Debruyne et al, 2003). At the end of the experiment, the rats were perfused under pentobarbital anesthesia and the brains were removed for histological verification of the cannulae placements.

\section{Statistical Analyses}

For all the experiments, brain reward thresholds and response latencies were expressed as percentages of the values obtained on the day before each test day. Percent changes in brain reward thresholds and response latencies were analyzed using a two-way repeated-measures analyses of variance (ANOVA) with the dose of D-Phe $\mathrm{CRF}_{(12-41)}$ as the within-subjects factor and pump content (saline or nicotine) as the between-subjects factor. For all experiments, statistically significant interactions in the ANOVA were followed by the Newman-Keuls post hoc test.

\section{RESULTS}

\section{Effect of D-Phe $\mathrm{CRF}_{(12-41)}$ Administered into the CeA on Precipitated Nicotine Withdrawal}

Mean $( \pm$ SEM) absolute brain reward thresholds before pump implantation for the saline- and nicotine-treated rats were $87.14 \pm 3.39$ and $88.23 \pm 6.66 \mu \mathrm{A} \quad(t(14)=0.15$, NS $)$, respectively. Mean ( \pm SEM) absolute response latencies for the saline- and nicotine-treated rats were $2.90 \pm 0.10$ and $3.08 \pm 0.15 \mathrm{~s}(t(14)=1.00$, NS $)$, respectively. Mecamylamine elevated the brain reward thresholds of the nicotine-treated rats, $146 \%$, and did not affect the brain reward thresholds of the control rats (Figure 1a; Treatment: F1,14=57.46, $P<0.0001)$. Mecamylamine did not affect the response latencies of the nicotine- or saline-treated rats (Figure $1 \mathrm{~b}$; Treatment: $\mathrm{F} 1,14=3.49$, NS). The administration of $\mathrm{D}-\mathrm{Phe}$ $\mathrm{CRF}_{(12-41)}$ into the CeA prevented the mecamylamineinduced elevations in brain reward thresholds in the nicotine-dependent rats and did not affect the brain reward thresholds of the rats that were chronically treated with saline (Figure 1a; Dose $\times$ Treatment interaction: $\mathrm{F} 3,42=4.21, P<0.011)$. Newman-Keuls post hoc comparisons indicated that $500 \mathrm{ng}$ of $\mathrm{D}-\mathrm{Phe} \mathrm{CRF}_{(12-41)}$ (unilateral dose) completely prevented the elevations in brain reward thresholds associated with precipitated nicotine withdrawal. D-Phe $\mathrm{CRF}_{(12-41)}$ did not affect the response latencies (Figure 1b; Dose: F3,42 $=1.23$, NS; Dose $\times$ Treatment interaction: $\mathrm{F} 3,42=0.17$, NS). See Figure $2 \mathrm{a}$ for a histological reconstruction of the injections sites.

\section{Effect of D-Phe $\mathrm{CRF}_{(12-41)}$ Administered into the lateral BNST on Precipitated Nicotine Withdrawal}

Mean $( \pm$ SEM) absolute brain reward thresholds before minipump implantation for the saline- and nicotine-treated rats were $118.84 \pm 8.78$ and $118.93 \pm 14.17 \mu \mathrm{A}(t(16)=0.01$, NS), respectively. Mean ( \pm SEM) absolute response latencies for the saline- and nicotine-treated rats were $3.28 \pm 0.16$ and $2.99 \pm 0.10 \mathrm{~s}(t(16)=1.61, \mathrm{NS})$, respectively. Similar to the first experiment, mecamylamine elevated the brain reward thresholds of the nicotine-treated rats, $147 \%$, and did not affect the brain reward thresholds of the salinetreated rats (Figure 3a; Treatment: $\mathrm{F} 1,16=17.33$, $P<0.0007)$. Mecamylamine did not affect the response latencies of the nicotine- or saline-treated rats (Figure $3 \mathrm{~b}$; Treatment: $F 1,16=3.21$, NS). The administration of $D-P h e$ $\mathrm{CRF}_{(12-41)}$ into the lateral BNST did not affect the brain reward thresholds (Dose: F3,48 $=0.64$, NS; Dose $\times$ Treat- 

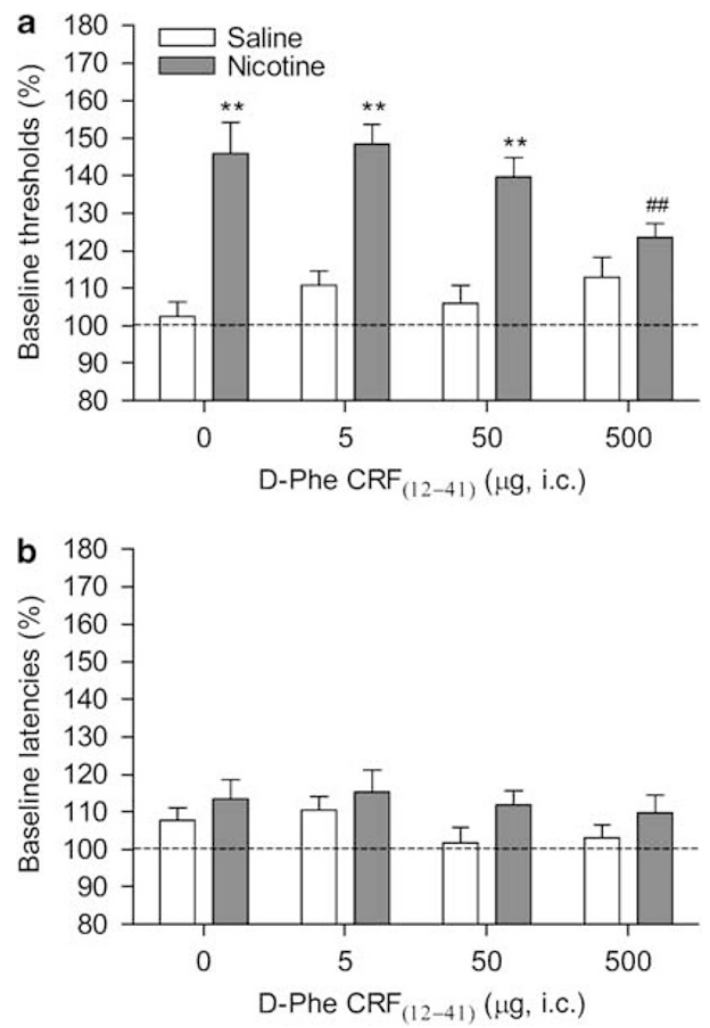

Figure I Effect of D-Phe $\mathrm{CRF}_{(|2-4|)}$ (saline, $n=8$; nicotine, $n=8$ ) administered into the central nucleus of the amygdala $(\mathrm{CeA})$ on the elevations in brain reward thresholds associated with mecamylamineprecipitated nicotine withdrawal (a). Effect of D-Phe $\mathrm{CRF}_{(12-41)}$ on the response latencies of rats chronically treated with saline $(n=8)$ or nicotine $(n=8)$ and acutely treated with mecamylamine (b). Brain reward thresholds and response latencies are expressed as a percentage of the pretest day values. D-Phe $\mathrm{CRF}_{(12-41)}$ was administered bilaterally and the figure depicts the unilateral dose. Asterisks $(* * P<0.0$ I) indicate elevations in brain reward thresholds compared to those of the corresponding salinetreated control group. Symbols (\#\# P<0.0I) indicate lower brain reward thresholds compared to those of rats chronically treated with nicotine and acutely treated with mecamylamine and vehicle ( $0 \mu \mathrm{g}$ of D-Phe $\left.\mathrm{CRF}_{(|2-4|)}\right)$. Abbreviation: i.c., intracranial.

ment: $\mathrm{F} 3,48=0.61, \mathrm{NS}$ ) or the response latencies (Dose: F3,48 $=0.92$, NS; Dose $\times$ Treatment: F3,48 $=2.40, \mathrm{NS}$ ) of the saline- or nicotine-treated rats. See Figure $2 \mathrm{~b}$ for $\mathrm{a}$ histological reconstruction of the injections sites.

\section{Effect of D-Phe $\mathrm{CRF}_{(12-41)}$ Administered into the Nacc Shell on Precipitated Nicotine Withdrawal}

Mean ( \pm SEM) absolute brain reward thresholds before minipump implantation for the saline- and nicotine-treated rats were $139.21 \pm 14.54$ and $136.99 \pm 15.18 \mu \mathrm{A}(t(16)=0.11$, $\mathrm{NS})$, respectively. Mean $( \pm \mathrm{SEM})$ absolute response latencies for the saline- and nicotine-treated rats were $3.61 \pm 0.17$ and $3.93 \pm 0.17 \mathrm{~s}(t(16)=1.33$, NS), respectively. Mecamylamine elevated the brain reward thresholds of the nicotinetreated rats, $151 \%$, and did not affect the brain reward thresholds of the saline-treated rats (Figure 4a; Treatment: $\mathrm{F} 1,16=59.44, P<0.0001)$. Mecamylamine did not affect the response latencies of the nicotine- or saline-treated rats (Figure 4b; Treatment: F1,16=0.77, NS). The administra- tion of $\mathrm{D}-\mathrm{Phe} \mathrm{CRF}_{(12-41)}$ into the Nacc shell prevented the mecamylamine-induced elevations in brain reward thresholds in the nicotine-dependent rats and did not affect the brain reward thresholds of the rats that were chronically treated with saline (Figure $4 \mathrm{a}$; Dose $\times$ Treatment interaction: $\mathrm{F} 3,48=3.48, P<0.023)$. Post hoc analysis indicated that the highest dose of D-Phe $\mathrm{CRF}_{(12-41)}, 500 \mathrm{ng}$ per site, completely prevented the mecamylamine-induced elevations in brain reward thresholds in the nicotine-treated rats. The administration of $\mathrm{D}-\mathrm{Phe} \mathrm{CRF}_{(12-41)}$ into the Nacc shell did not affect the response latencies of the saline- or nicotine-treated rats (Dose: F3,48 $=0.35$, NS; Dose $\times$ Treatment: F3,48=1.07, NS). See Figure 2c for a histological reconstruction of the injections sites.

\section{DISCUSSION}

These results demonstrate that the nAChR antagonist mecamylamine elevates the brain reward thresholds of rats that are chronically treated with nicotine and does not affect the brain reward thresholds of saline-treated control rats, which is in line with previous studies (Bruijnzeel and Markou, 2004; Epping-Jordan et al, 1998; Watkins et al, 2000). The administration of D-Phe $\mathrm{CRF}_{(12-41)}$ (500 ng per site, unilateral dose) into the CeA and the Nacc shell prevented the mecamylamine-induced elevations in brain reward thresholds. In contrast, the administration of $\mathrm{D}-\mathrm{Phe}$ $\mathrm{CRF}_{(12-41)}$ into the lateral BNST did not prevent the elevations in brain reward thresholds associated with precipitated nicotine withdrawal. Our findings extend and corroborate previous findings by demonstrating that antagonism of CRF1/2 receptors in the CeA and Nacc shell, but not in the lateral BNST, prevents the negative affective state of precipitated nicotine withdrawal in rats (Bruijnzeel et al, 2007; Epping-Jordan et al, 1998).

These studies focused on investigating the importance of CRF in the CeA, lateral BNST, and Nacc shell in nicotine withdrawal as all of these structures are considered part of the extended amygdala, are highly interconnected, and have overlapping afferent and efferent connections (Alheid and Heimer, 1988; Heimer et al, 1991). In addition, it has been suggested that the extended amygdala has an important function in the negative affective state associated with drug withdrawal (Koob and Le Moal, 2005). Extensive evidence points toward a function for $\mathrm{CRF}$ in the CeA in drug addictions. Withdrawal from alcohol (Merlo Pich et al, 1995), cannabis (Rodriguez de Fonseca et al, 1997), cocaine (Richter and Weiss, 1999), and nicotine (George et al, 2007) has been shown to induce an increased release of CRF in the CeA. It has also been shown that alcohol withdrawalinduced anxiety-like behavior in the elevated plus maze test can be reversed by the administration of the nonspecific CRF1/2 receptor antagonist $\alpha$-helical $\mathrm{CRF}_{(9-41)}$ in the lateral ventricles (Baldwin et al, 1991) or the CeA (Rassnick et al, 1993). Koob and colleagues demonstrated that alcohol intake in rats is increased after chronic exposure to alcohol vapor (Roberts et al, 2000) and the increased alcohol intake in the alcohol-dependent animals can be prevented by the administration of D-Phe $\mathrm{CRF}_{(12-41)}$ into the CeA before the alcohol self-administration sessions (Funk et al, 2006). The results of our study demonstrated that antagonism of CRF 

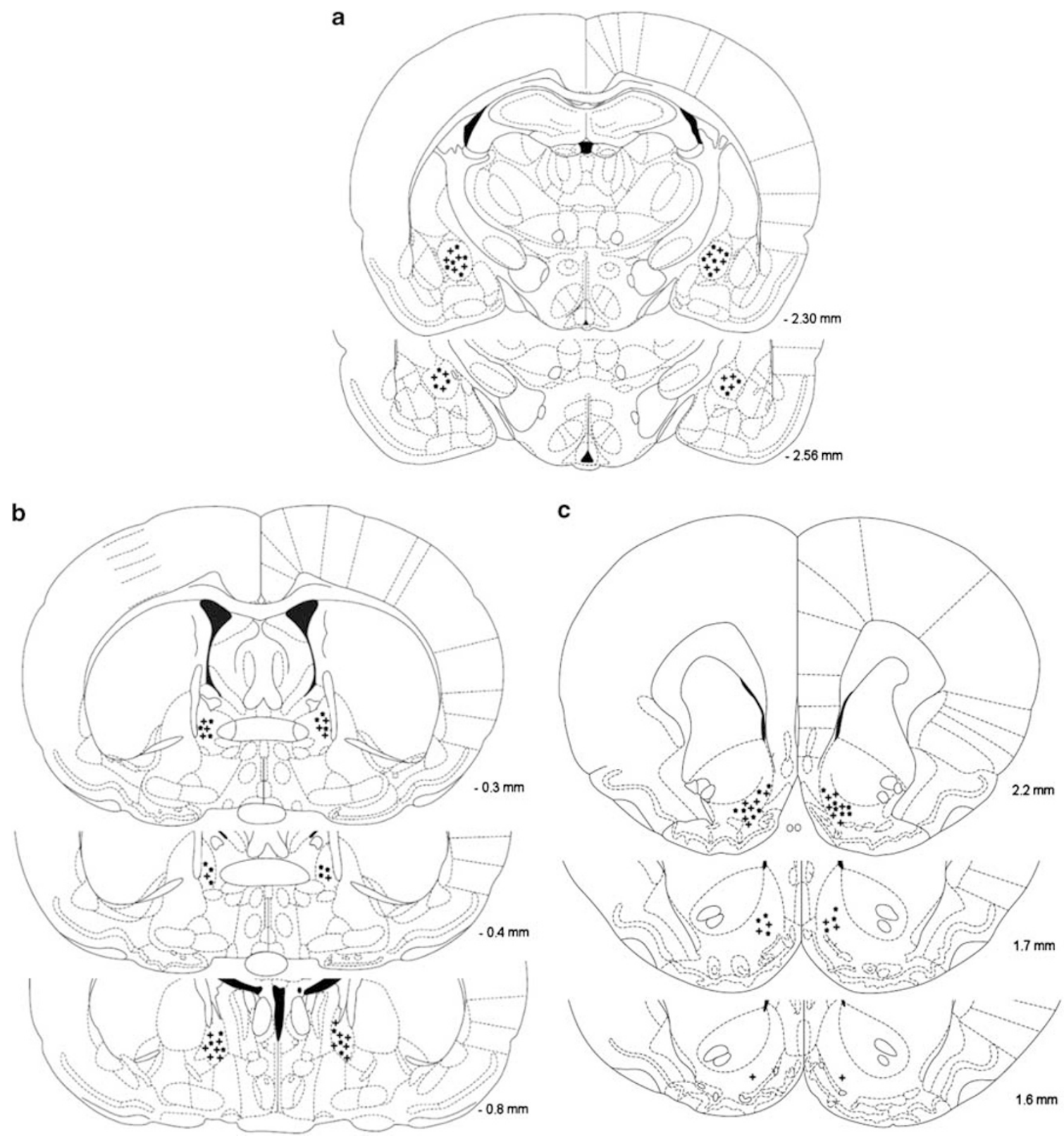

Figure 2 Histological reconstruction of bilateral injection sites in the central nucleus of the amygdala (CeA) (a) of rats chronically treated with nicotine $(+, n=8)$ or saline $(*, n=8)$. Reconstruction of bilateral injection sites in the lateral bed nucleus of the stria terminalis (BNST) (b) of rats chronically treated with nicotine $(+, n=9)$ or saline (*, $n=9$ ). Reconstruction of bilateral injections sites in the nucleus accumbens shell (Nacc shell) (c) of rats chronically treated with nicotine $(+, n=9)$ or saline $(*, n=9)$. The figures are copies from the Paxinos and Watson brain atlas (Paxinos and Watson, 1998).

receptors in the CeA prevented the elevations in brain reward thresholds associated with nicotine withdrawal. This suggests that the release of CRF into the CeA may at least partly mediate the deficit in brain reward function associated with nicotine withdrawal. Drug intake during the withdrawal phase could possibly diminish negative affective states by decreasing the release of CRF in the CeA.

The intra-CeA dose of D-Phe $\mathrm{CRF}_{(12-41)}$ that prevented the elevations in brain reward thresholds was about 20 times lower than the i.c.v. dose required to prevent the elevations in brain reward thresholds associated with nicotine withdrawal ( $1 \mu \mathrm{g}$ intra-CeA [total bilateral dose] vs $20 \mu$ g i.c.v.) (Bruijnzeel et al, 2007). This suggests that the current total bilateral dose, $1 \mu \mathrm{g}$ of D-Phe $\mathrm{CRF}_{(12-41)}$, would not have prevented the deficit in brain reward function associated with nicotine withdrawal when administered into the lateral ventricles. This rules out the possibility that in these studies D-Phe $\mathrm{CRF}_{(12-41)}$ diffused into the lateral ventricles and then mediated its effects by acting on other brain sites. It is also unlikely that D-Phe $\operatorname{CRF}_{(12-41)}$ prevented the elevations in brain reward thresholds by activating brain reward systems. The i.c.v. administration of D-Phe $\mathrm{CRF}_{(12-41)}$ does not alter brain reward thresholds in drug-free rats (Macey et al, 2000). In addition, in this study we showed that intra-CeA, lateral BNST, or Nacc shell administration of D-Phe $\mathrm{CRF}_{(12-41)}$ does not affect the brain reward thresholds of the chronic saline/acute mecamylamine control group. 

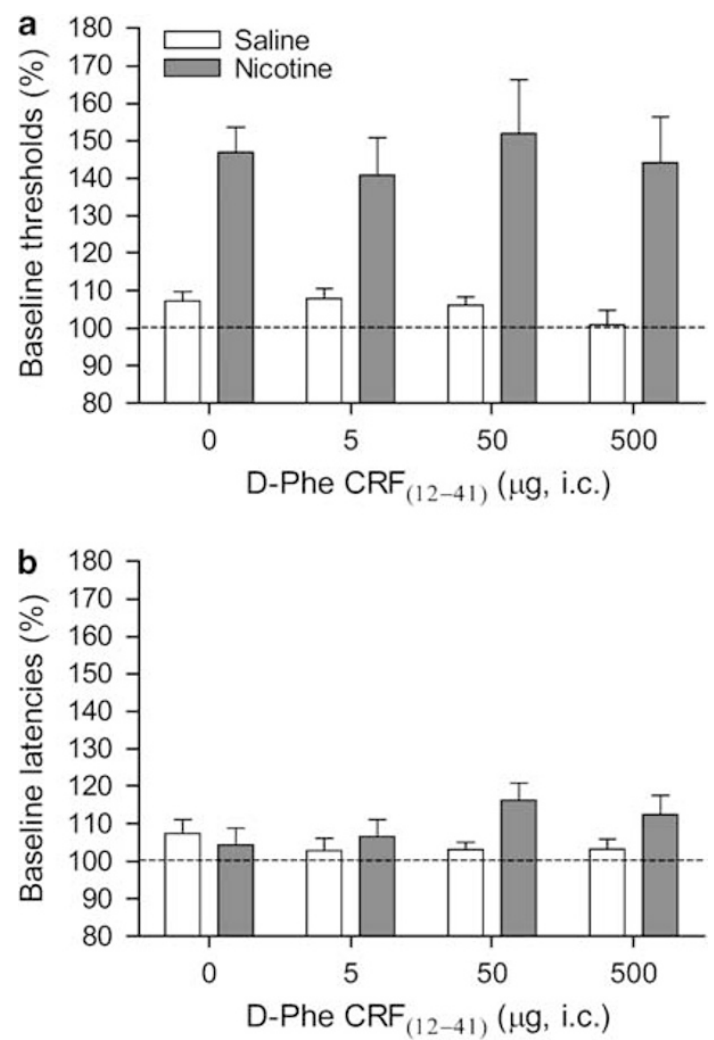

Figure 3 Effect of D-Phe $\mathrm{CRF}_{(|2-4|)}$ (saline, $n=9$; nicotine, $n=9$ ) administered into the lateral bed nucleus of the stria terminalis (BNST) on the elevations in brain reward thresholds associated with mecamylamineprecipitated nicotine withdrawal (a). Effect of D-Phe $\mathrm{CRF}_{(12-41)}$ on the response latencies of rats chronically treated with saline $(n=8)$ or nicotine $(n=8)$ and acutely treated with mecamylamine (b). Brain reward thresholds and response latencies are expressed as a percentage of the pretest day values. D-Phe $\mathrm{CRF}_{(12-41)}$ was administered bilaterally and the figure depicts the unilateral dose. Abbreviation: i.c., intracranial.

Some studies suggest that the BNST may be involved in specific aspects of drug addictions. Discontinuation of chronic alcohol administration increases extracellular CRF levels in the BNST, which subsides with subsequent alcohol intake (Olive et al, 2002). In addition, naloxone induces a dose-dependent increase in c-fos mRNA in the BNST of morphine-dependent animals (Frenois et al, 2002). Evidence for a function of the BNST in negative affective states is provided by Aston-Jones and colleagues (Delfs et al, 2000). They reported that the blockade of $\beta$-noradrenergic receptors or activation of $\alpha 2$-adrenergic receptors in the BNST prevents opioid withdrawal-induced conditioned place aversion. At this point in time, we are not aware of any studies which reported that blockade of CRF receptors in the lateral BNST prevents the negative affective state associated with drug withdrawal. The results of our study suggest that the activation of CRF receptors in the lateral BNST does not have a function in the negative emotional state associated with nicotine withdrawal. This is in agreement with a previous study showing that blockade of CRF receptors in the BNST does not reduce alcohol intake in alcohol-dependent rats (Funk et al, 2006). It is unlikely that the doses of D-Phe $\mathrm{CRF}_{(12-41)}$ were too low in this study as the same doses prevented the negative
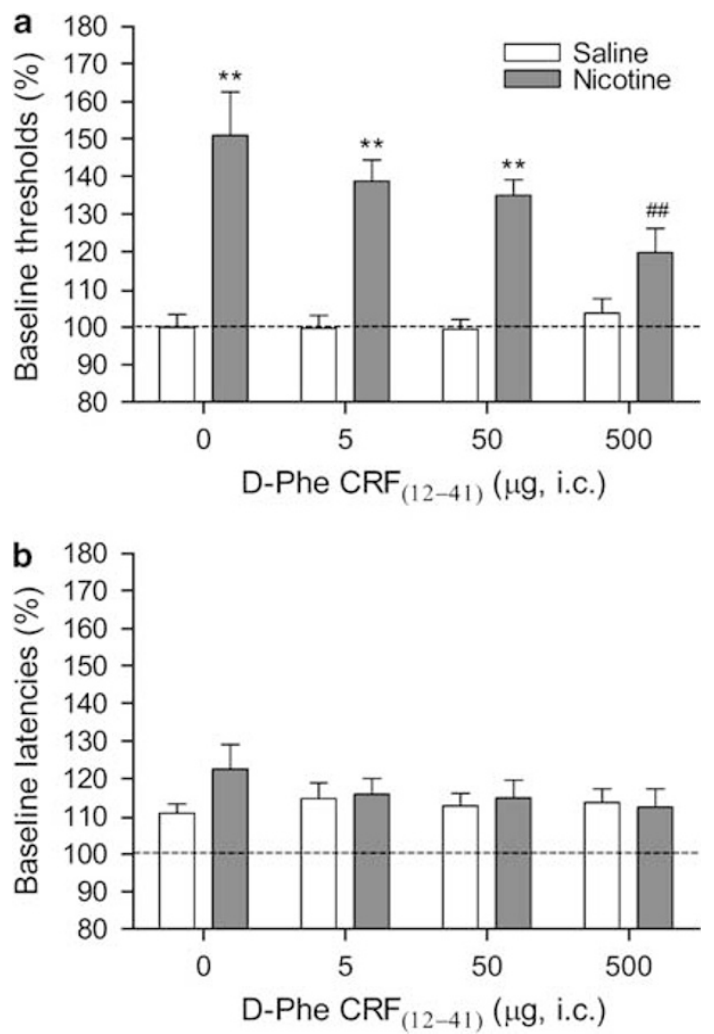

Figure 4 Effect of D-Phe $\mathrm{CRF}_{(|2-4|)}$ (saline, $n=9$; nicotine, $n=9$ ) administered into the nucleus accumbens shell (Nacc shell) on the elevations in brain reward thresholds associated with mecamylamineprecipitated nicotine withdrawal (a). Effect of D-Phe $\mathrm{CRF}_{(12-41)}$ on the response latencies of rats chronically treated with saline $(n=9)$ or nicotine $(n=9)$ and acutely treated with mecamylamine (b). Brain reward thresholds and response latencies are expressed as a percentage of the pretest day values. D-Phe $\mathrm{CRF}_{(12-41)}$ was administered bilaterally and the figure depicts the unilateral dose. Asterisks $(* * P<0.0 \mathrm{I})$ indicate elevations in brain reward thresholds compared to those of the corresponding salinetreated control group. Symbols $(\# \# P<0.01$ ) indicate lower brain reward thresholds compared to those of rats chronically treated with nicotine and acutely treated with mecamylamine and vehicle $\left(0 \mu \mathrm{g}\right.$ of D-Phe $\left.\mathrm{CRF}_{(|2-4|)}\right)$. Abbreviation: i.c., intracranial.

emotional state associated with nicotine withdrawal when administered into the CeA or Nacc shell. In addition, a previous study reported that the intra-BNST administration of doses of D-Phe $\mathrm{CRF}_{(12-41)}$, which are within the current dose-response range (10 or $50 \mathrm{ng}$ per side administered bilaterally), prevent stress-induced reinstatement of cocaine seeking behavior (Erb and Stewart, 1999).

Emerging evidence suggests that $\mathrm{CRF}$ in the $\mathrm{CeA}$ and BNST may have a distinct function in various aspects of drug addictions and anxiety and fear responses (Erb and Stewart, 1999; Walker et al, 2003). These studies suggest that CRF in the CeA, but not in the lateral BNST, is important in the negative affective state associated with nicotine withdrawal. CRF in the CeA, but not in the BNST, has also been suggested to be important in the increased alcohol intake in alcohol-dependent animals (Funk et al, 2006). Furthermore, the administration of the CRF1/2 receptor antagonist $\alpha$-helical $\mathrm{CRF}_{(9-41)}$ into the CeA, but not into the BNST, reduced the severity of naloxoneprecipitated somatic morphine withdrawal signs (McNally and Akil, 2002). The aforementioned studies suggest that 
CRF signaling in the CeA mediates acute drug withdrawal signs such as elevations in brain reward thresholds, somatic signs, and increased drug intake. In contrast, CRF transmission in the BNST may at least partly mediate protracted drug withdrawal signs such as stress-induced reinstatement of drug seeking behavior. For example, Erb and Stewart (1999) demonstrated that the BNST, but not the $\mathrm{CeA}$, has an important function in stress-induced reinstatement of cocaine seeking behavior.

Neurochemical changes in the Nacc shell have been implicated in the negative affective state associated with drugs withdrawal. For example, nicotine withdrawal has been associated with a decrease in dopamine levels and an increase in acetylcholine levels in the Nacc shell in rats (Rada et al, 2001). The Nacc shell contains CRF-immunoreactive cells and moderate levels of CRF1 and CRF2 receptors have been detected in this brain site (De Souza et al, 1985; Merchenthaler et al, 1982; Rominger et al, 1998; Swanson et al, 1983). However, very little research has been conducted to investigate the function of CRF in the Nacc shell in drug addiction. The results of this study indicate that the administration of the CRF1/2 receptor antagonist D-Phe $\mathrm{CRF}_{(12-41)}$ into the Nacc shell prevents the elevations in brain reward thresholds associated with precipitated nicotine withdrawal. Thus, this suggests that the negative affective state associated with nicotine withdrawal is at least partly mediated by the release of CRF in the Nacc shell. Research by Koob and colleagues suggests that CRF in the Nacc shell does not have a function in alcohol intake in alcohol-dependent rats (Funk et al, 2006). However, emerging evidence suggests that CRF in the Nacc shell has behavioral effects and could be important in psychiatric disorders. The i.c.v. administration of CRF has been shown to increase locomotor activity in rats in a familiar environment and to increase anxiety-like behavior in a novel environment (Sutton et al, 1982; Takahashi et al, 1989). Kelley and colleagues demonstrated that the administration of CRF into the Nacc shell also increases locomotor activity in rats in a familiar environment (Holahan et al, 1997), which suggests that CRF might mediate some of its behavioral effects by stimulating CRF receptors in the Nacc shell. In a recent study it was demonstrated that the administration of CRF into the Nacc shell increases cueinduced motivation to obtain sucrose pellets (Pecina et al, 2006). It was suggested that the CRF release in the Nacc shell may also increase the motivation to obtain other positive reinforcers such as drugs of abuse and therefore have an important function in the reinstatement of drug seeking behavior.

$\mathrm{D}-\mathrm{Phe} \mathrm{CRF}_{(12-41)}$ is a nonspecific CRF receptor antagonist and therefore these studies did not distinguish between CRF1 and CRF2 receptor subtypes. Extensive evidence suggests that the CRF1 receptor has a pivotal function in drug withdrawal and relapse. Systemic administration of the small-molecule nonpeptide CRF1 receptor antagonist MPZP has been shown to decrease nicotine withdrawal-induced anxiety-like behavior and to prevent increased nicotine intake after a period of abstinence (George et al, 2007). Furthermore, the nonpeptide CRF1 receptor antagonist MTIP blocks alcohol withdrawal-induced anxiety-like behavior, excessive alcohol self-administration in alcoholdependent rats, and stress-induced reinstatement of alcohol seeking behavior (Gehlert et al, 2007). Conflicting findings have been reported with regard to the function of the CRF2 receptor in drug withdrawal. Stimulation of CRF2 receptors decreases alcohol intake in alcohol-dependent animals and decreases alcohol withdrawal-induced anxiety-like behavior (Funk and Koob, 2007; Valdez et al, 2004). In contrast, CRF2 receptor knockout mice display decreased somatic morphine withdrawal signs, which suggests that activation of CRF2 receptors contributes to drug withdrawal (Papaleo et al, 2008). The above-discussed studies would suggest that the activation of the CRF1 receptor may have an important function in the negative affective state of nicotine withdrawal. At this point in time, additional studies are needed before firm conclusions can be drawn about the function of the CRF2 receptor in drug withdrawal.

In these studies, the function of CRF in nicotine withdrawal was investigated in rats passively exposed to nicotine. It should be noted that passive exposure to nicotine and nicotine self-administration may have different effects on brain chemistry and brain reward function (Epping-Jordan et al, 1998; Jacobs et al, 2003; Kenny and Markou, 2006). Therefore, additional studies are warranted to investigate the function of CRF in changes in brain reward function after discontinuing chronic nicotine selfadministration. Previous research has shown that extended access to nicotine self-administration, $23 \mathrm{~h}$ per day, leads to nicotine dependence as indicated by precipitated somatic withdrawal signs (O'Dell et al, 2007). Somatic withdrawal signs were not recorded in this study. However, future studies may investigate the effect of the administration of CRF receptor antagonists in specific brain sites on affective and somatic withdrawal signs as this may help to delineate the neuronal substrates underlying the negative affective and somatic withdrawal signs.

Taken together, these findings indicate that blockade of CRF1/2 receptors in the CeA and Nac Shell, but not in the lateral BNST, prevents the elevations in brain reward thresholds associated with precipitated nicotine withdrawal. These studies point toward an important function for CRF in the $\mathrm{CeA}$ and Nacc shell in the negative affective state associated with smoking cessation. Further studies are warranted to investigate the function of specific CRF receptor subtypes in the extended amygdala in the negative affective state associated with smoking cessation.

\section{ACKNOWLEDGEMENTS}

This work was funded by National Institute on Drug Abuse grants (DA023575 and DA020504) to Adrie Bruijnzeel. We thank Dr Jean Rivier (The Clayton Foundation Laboratories for Peptide Biology, The Salk Institute for Biological Studies, San Diego, CA) for generously providing D-Phe $\mathrm{CRF}_{(12-41)}$.

\section{DISCLOSURE/CONFLICT OF INTEREST}

The author(s) declare that except for income received from primary employer, no financial support or compensation has been received from any individual or corporate entity over the past 3 years for research or professional service and there are no personal financial holdings that could be perceived as constituting a potential conflict of interest. 


\section{REFERENCES}

Alheid GF, Heimer L (1988). New perspectives in basal forebrain organization of special relevance for neuropsychiatric disorders: the striatopallidal, amygdaloid, and corticopetal components of substantia innominata. Neuroscience 27: 1-39.

American Psychiatric Association (2000). Diagnostic and Statistical Manual of Mental Disorders. American Psychiatric Press: Washington, DC.

Baldwin HA, Rassnick S, Rivier J, Koob GF, Britton KT (1991). CRF antagonist reverses the 'anxiogenic' response to ethanol withdrawal in the rat. Psychopharmacology (Berl) 103: 227-232.

Bardo MT, Green TA, Crooks PA, Dwoskin LP (1999). Nornicotine is self-administered intravenously by rats. Psychopharmacology (Berl) 146: 290-296.

Barr AM, Markou A (2005). Psychostimulant withdrawal as an inducing condition in animal models of depression. Neurosci Biobehav Rev 29: 675-706.

Barr AM, Markou A, Phillips AG (2002). A 'crash' course on psychostimulant withdrawal as a model of depression. Trends Pharmacol Sci 23: 475-482.

Basso AM, Spina M, Rivier J, Vale W, Koob GF (1999). Corticotropin-releasing factor antagonist attenuates the 'anxiogenic-like' effect in the defensive burying paradigm but not in the elevated plus-maze following chronic cocaine in rats. Psychopharmacology (Berl) 145: 21-30.

Bruijnzeel AW, Gold MS (2005). The role of corticotropin-releasing factor-like peptides in cannabis, nicotine, and alcohol dependence. Brain Res Brain Res Rev 49: 505-528.

Bruijnzeel AW, Lewis B, Bajpai LK, Morey TE, Dennis DM, Gold M (2006). Severe deficit in brain reward function associated with fentanyl withdrawal in rats. Biol Psychiatry 59: 477-480.

Bruijnzeel AW, Markou A (2004). Adaptations in cholinergic transmission in the ventral tegmental area associated with the affective signs of nicotine withdrawal in rats. Neuropharmacology 47: 572-579.

Bruijnzeel AW, Zislis G, Wilson C, Gold MS (2007). Antagonism of CRF receptors prevents the deficit in brain reward function associated with precipitated nicotine withdrawal in rats. Neuropsychopharmacology 32: 955-963.

Corrigall WA, Coen KM (1989). Nicotine maintains robust selfadministration in rats on a limited-access schedule. Psychopharmacology (Berl) 99: 473-478.

Corrigall WA, Coen KM, Adamson KL (1994). Self-administered nicotine activates the mesolimbic dopamine system through the ventral tegmental area. Brain Res 653: 278-284.

Crooks PA, Dwoskin LP (1997). Contribution of CNS nicotine metabolites to the neuropharmacological effects of nicotine and tobacco smoking. Biochem Pharmacol 54: 743-753.

De Souza EB, Insel TR, Perrin MH, Rivier J, Vale WW, Kuhar MJ (1985). Corticotropin-releasing factor receptors are widely distributed within the rat central nervous system: an autoradiographic study. J Neurosci 5: 3189-3203.

Debruyne D, Sobrio F, Hinschberger A, Camsonne R, Coquerel A, Barre L (2003). Short-term pharmacokinetics and brain distribution of mecamylamine as a preliminary to carbon-11 labeling for nicotinic receptor investigation. J Pharm Sci 92: 1051-1057.

Delfs JM, Zhu Y, Druhan JP, Aston-Jones G (2000). Noradrenaline in the ventral forebrain is critical for opiate withdrawal-induced aversion. Nature 403: 430-434.

Donny EC, Caggiula AR, Mielke MM, Booth S, Gharib MA, Hoffman A et al. (1999). Nicotine self-administration in rats on a progressive ratio schedule of reinforcement. Psychopharmacology (Berl) 147: 135-142.

Epping-Jordan MP, Watkins SS, Koob GF, Markou A (1998). Dramatic decreases in brain reward function during nicotine withdrawal. Nature 393: 76-79.
Erb S, Stewart J (1999). A role for the bed nucleus of the stria terminalis, but not the amygdala, in the effects of corticotropinreleasing factor on stress-induced reinstatement of cocaine seeking. J Neurosci 19: RC35.

Frenois F, Cador M, Caille S, Stinus L, Le MC (2002). Neural correlates of the motivational and somatic components of naloxone-precipitated morphine withdrawal. Eur J Neurosci 16: 1377-1389.

Funk CK, Koob GF (2007). A CRF(2) agonist administered into the central nucleus of the amygdala decreases ethanol self-administration in ethanol-dependent rats. Brain Res 1155: 172-178.

Funk CK, O’Dell LE, Crawford EF, Koob GF (2006). Corticotropinreleasing factor within the central nucleus of the amygdala mediates enhanced ethanol self-administration in withdrawn, ethanol-dependent rats. J Neurosci 26: 11324-11332.

Gehlert DR, Cippitelli A, Thorsell A, Le AD, Hipskind PA, Hamdouchi C et al. (2007). 3-(4-Chloro-2-morpholin-4-ylthiazol-5-yl)-8-(1-ethylpropyl)-2,6-dimethyl-imidazo[1,2-b]pyridazine: a novel brain-penetrant, orally available corticotropinreleasing factor receptor 1 antagonist with efficacy in animal models of alcoholism. J Neurosci 27: 2718-2726.

George O, Ghozland S, Azar MR, Cottone P, Zorrilla EP, Parsons LH et al. (2007). CRF CRF1 system activation mediates withdrawal-induced increases in nicotine self-administration in nicotine-dependent rats. Proc Natl Acad Sci USA 104: 1719817203.

Gulyas J, Rivier C, Perrin M, Koerber SC, Sutton S, Corrigan A et al. (1995). Potent, structurally constrained agonists and competitive antagonists of corticotropin-releasing factor. Proc Natl Acad Sci USA 92: 10575-10579.

Harrison AA, Liem YT, Markou A (2001). Fluoxetine combined with a serotonin-1A receptor antagonist reversed reward deficits observed during nicotine and amphetamine withdrawal in rats. Neuropsychopharmacology 25: 55-71.

Heimer L, de Olmos J, Alheid GF, Zaborszky L (1991). 'Perestroika' in the basal forebrain: opening the border between neurology and psychiatry. Prog Brain Res 87: 109-165.

Holahan MR, Kalin NH, Kelley AE (1997). Microinfusion of corticotropin-releasing factor into the nucleus accumbens shell results in increased behavioral arousal and oral motor activity. Psychopharmacology (Berl) 130: 189-196.

Jacobs EH, Smit AB, De Vries TJ, Schoffelmeer AN (2003). Neuroadaptive effects of active versus passive drug administration in addiction research. Trends Pharmacol Sci 24: 566-573.

Kenny PJ, Markou A (2006). Nicotine self-administration acutely activates brain reward systems and induces a long-lasting increase in reward sensitivity. Neuropsychopharmacology 31: 1203-1211.

Koob GF (2008). A role for brain stress systems in addiction. Neuron 59: 11-34.

Koob GF, Caine SB, Parsons L, Markou A, Weiss F (1997). Opponent process model and psychostimulant addiction. Pharmacol Biochem Behav 57: 513-521.

Koob GF, Le Moal M (2005). Plasticity of reward neurocircuitry and the 'dark side' of drug addiction. Nat Neurosci 8: 1442-1444.

Kornetsky C, Esposito RU (1979). Euphorigenic drugs: effects on the reward pathways of the brain. Fed Proc 38: 2473-2476.

Macey DJ, Koob GF, Markou A (2000). CRF and urocortin decreased brain stimulation reward in the rat: reversal by a CRF receptor antagonist. Brain Res 866: 82-91.

Malin DH, Lake JR, Newlin-Maultsby P, Roberts LK, Lanier JG, Carter VA et al. (1992). Rodent model of nicotine abstinence syndrome. Pharmacol Biochem Behav 43: 779-784.

Markou A, Koob GF (1992). Construct validity of a self-stimulation threshold paradigm: effects of reward and performance manipulations. Physiol Behav 51: 111-119. 
Markou A, Kosten TR, Koob GF (1998). Neurobiological similarities in depression and drug dependence: a self-medication hypothesis. Neuropsychopharmacology 18: 135-174.

McLellan AT, Lewis DC, O'Brien CP, Kleber HD (2000). Drug dependence, a chronic medical illness: implications for treatment, insurance, and outcomes evaluation. JAMA 284: 1689-1695.

McNally GP, Akil H (2002). Role of corticotropin-releasing hormone in the amygdala and bed nucleus of the stria terminalis in the behavioral, pain modulatory, and endocrine consequences of opiate withdrawal. Neuroscience 112: 605-617.

Merchenthaler I, Vigh S, Petrusz P, Schally AV (1982). Immunocytochemical localization of corticotropin-releasing factor (CRF) in the rat brain. Am J Anat 165: 385-396.

Merlo Pich E, Lorang M, Yeganeh M, Rodriguez de Fonseca F, Raber J, Koob GF et al. (1995). Increase of extracellular corticotropin-releasing factor-like immunoreactivity levels in the amygdala of awake rats during restraint stress and ethanol withdrawal as measured by microdialysis. J Neurosci 15: 5439-5447.

Nemeroff CB, Widerlov E, Bissette G, Walleus H, Karlsson I, Eklund $\mathrm{K}$ et al. (1984). Elevated concentrations of CSF corticotropin-releasing factor-like immunoreactivity in depressed patients. Science 226: 1342-1344.

$\mathrm{O}^{\prime}$ Brien CP (2003). Research advances in the understanding and treatment of addiction. Am J Addict 12(Suppl 2): S36-S47.

O'Dell LE, Chen SA, Smith RT, Specio SE, Balster RL, Paterson NE et al. (2007). Extended access to nicotine self-administration leads to dependence: circadian measures, withdrawal measures, and extinction behavior in rats. J Pharmacol Exp Ther 320: $180-193$.

Olive MF, Koenig HN, Nannini MA, Hodge CW (2002). Elevated extracellular CRF levels in the bed nucleus of the stria terminalis during ethanol withdrawal and reduction by subsequent ethanol intake. Pharmacol Biochem Behav 72: 213-220.

Overstreet DH, Knapp DJ, Breese GR (2004). Modulation of multiple ethanol withdrawal-induced anxiety-like behavior by CRF and CRF1 receptors. Pharmacol Biochem Behav 77: 405-413.

Papaleo F, Ghozland S, Ingallinesi M, Roberts AJ, Koob GF, Contarino A (2008). Disruption of the CRF(2) receptor pathway decreases the somatic expression of opiate withdrawal. Neuropsychopharmacology 33: 2878-2887.

Paxinos G, Watson C (1998). The rat brain in stereotaxic coordinates. Academic Press: San Diego.

Pecina S, Schulkin J, Berridge KC (2006). Nucleus accumbens corticotropin-releasing factor increases cue-triggered motivation for sucrose reward: paradoxical positive incentive effects in stress? BMC Biol 4: 8.

Perrin MH, Sutton SW, Cervini LA, Rivier JE, Vale WW (1999). Comparison of an agonist, urocortin, and an antagonist, astressin, as radioligands for characterization of corticotropinreleasing factor receptors. J Pharmacol Exp Ther 288: 729-734.

Picciotto MR, Zoli M, Rimondini R, Lena C, Marubio LM, Merlo Pich E et al. (1998). Acetylcholine receptors containing the beta2 subunit are involved in the reinforcing properties of nicotine. Nature 391: 173-177.

Rada P, Jensen K, Hoebel BG (2001). Effects of nicotine and mecamylamine-induced withdrawal on extracellular dopamine and acetylcholine in the rat nucleus accumbens. Psychopharmacology (Berl) 157: 105-110.
Rassnick S, Heinrichs SC, Britton KT, Koob GF (1993). Microinjection of a corticotropin-releasing factor antagonist into the central nucleus of the amygdala reverses anxiogenic-like effects of ethanol withdrawal. Brain Res 605: 25-32.

Richter RM, Weiss F (1999). In vivo CRF release in rat amygdala is increased during cocaine withdrawal in self-administering rats. Synapse 32: 254-261.

Roberts AJ, Heyser CJ, Cole M, Griffin P, Koob GF (2000). Excessive ethanol drinking following a history of dependence: animal model of allostasis. Neuropsychopharmacology 22: 581-594.

Rodriguez de Fonseca F, Carrera MR, Navarro M, Koob GF, Weiss F (1997). Activation of corticotropin-releasing factor in the limbic system during cannabinoid withdrawal. Science 276: 2050-2054.

Rominger DH, Rominger CM, Fitzgerald LW, Grzanna R, Largent BL, Zaczek R (1998). Characterization of [125I]sauvagine binding to $\mathrm{CRH} 2$ receptors: membrane homogenate and autoradiographic studies. J Pharmacol Exp Ther 286: 459-468.

Sarnyai Z, Biro E, Gardi J, Vecsernyes M, Julesz J, Telegdy G (1995). Brain corticotropin-releasing factor mediates 'anxietylike' behavior induced by cocaine withdrawal in rats. Brain Res 675: 89-97.

Schulteis G, Markou A, Cole M, Koob GF (1995). Decreased brain reward produced by ethanol withdrawal. Proc Natl Acad Sci USA 92: $5880-5884$.

Stolerman IP, Jarvis MJ (1995). The scientific case that nicotine is addictive. Psychopharmacology (Berl) 117: 2-10.

Sutton RE, Koob GF, Le Moal M, Rivier J, Vale W (1982). Corticotropin releasing factor produces behavioural activation in rats. Nature 297: 331-333.

Swanson LW, Sawchenko PE, Rivier J, Vale WW (1983). Organization of ovine corticotropin-releasing factor immunoreactive cells and fibers in the rat brain: an immunohistochemical study. Neuroendocrinology 36: 165-186.

Takahashi LK, Kalin NH, Vanden Burgt JA, Sherman JE (1989). Corticotropin-releasing factor modulates defensivewithdrawal and exploratory behavior in rats. Behav Neurosci 103: 648-654.

Valdez GR, Sabino V, Koob GF (2004). Increased anxiety-like behavior and ethanol self-administration in dependent rats: reversal via corticotropin-releasing factor-2 receptor activation. Alcohol Clin Exp Res 28: 865-872.

Walker DL, Toufexis DJ, Davis M (2003). Role of the bed nucleus of the stria terminalis versus the amygdala in fear, stress, and anxiety. Eur J Pharmacol 463: 199-216.

Watkins SS, Epping-Jordan MP, Koob GF, Markou A (1999). Blockade of nicotine self-administration with nicotinic antagonists in rats. Pharmacol Biochem Behav 62: 743-751.

Watkins SS, Stinus L, Koob GF, Markou A (2000). Reward and somatic changes during precipitated nicotine withdrawal in rats: centrally and peripherally mediated effects. J Pharmacol Exp Ther 292: 1053-1064.

Wise RA, Munn E (1995). Withdrawal from chronic amphetamine elevates baseline intracranial self-stimulation thresholds. Psychopharmacology (Berl) 117: 130-136.

Zobel AW, Nickel T, Kunzel HE, Ackl N, Sonntag A, Ising M et al. (2000). Effects of the high-affinity corticotropin-releasing hormone receptor 1 antagonist R121919 in major depression: the first 20 patients treated. J Psychiatr Res 34: 171-181. 